\title{
Pediatric pancreaticopleural fistula: magnetic resonance imaging findings
}

\author{
Sinem Aydin, Rasul Sharifov, Serpil Kurtcan, Gizem Timocin, Alpay Alkan
}

Radiology Department, Bezmialem Vakif University, Istanbul, Turkey

Submitted: 2 July 2016

Accepted: 16 August 2016

Arch Med Sci Civil Dis 2016; 1: e70-e72

DOI: 10.5114 /amscd.2016.61979

Copyright @ 2016 Termedia \& Banach

Pancreaticopleural fistula (PPF) is a rare but severe complication of chronic pancreatitis $[1,2]$. Patients diagnosed with PPF are commonly middle-aged (40-50 years) male patients (83\%), with chronic pancreatitis related mainly to alcohol abuse (67\%) [3]. It is very rare in the pediatric population due to lower incidence of chronic pancreatitis compared with adults. A pancreatic pleural effusion develops due to direct passage of pancreatic exudate through a natural hiatus in the diaphragm or by direct penetration through the dome of the diaphragm from a neighboring subdiaphragmatic collection [3]. Diagnosis can be late because of dominance of thoracic signs and symptoms. We review here key points in non-invasive diagnosis of a pancreaticopleural fistula with emphasis on magnetic resonance imaging (MRI) findings.

A 14-year-old girl presented with left sided chest pain and fever ongoing for a few days. She had a history of hospitalization due to pleural effusion. She had been also admitted to emergency room (ER) for recurrent abdominal pain. She had abdominal pain every day. At physical examination she had a fever about $38.5^{\circ} \mathrm{C}$. Laboratory tests were normal. She had normal white blood cell count (WBC) level and C-reactive protein (CRP). Chest $X$-ray revealed a homogeneous opacity in left lower zone with pleural effusion (Figure $1 \mathrm{~A}$ ). Effusion sample was hemorrhagic. Considering the

\author{
Corresponding author: \\ Dr. Sinem Aydin \\ Radiology Department \\ Bezmialem Vakif University \\ Adnan Menderes Avenue \\ Vatan Street Fatih \\ 34093 Istanbul, Turkey \\ Phone: +90 2124531700 \\ Fax: +90 2126217580 \\ E-mail: drsinem@mynet.com
}
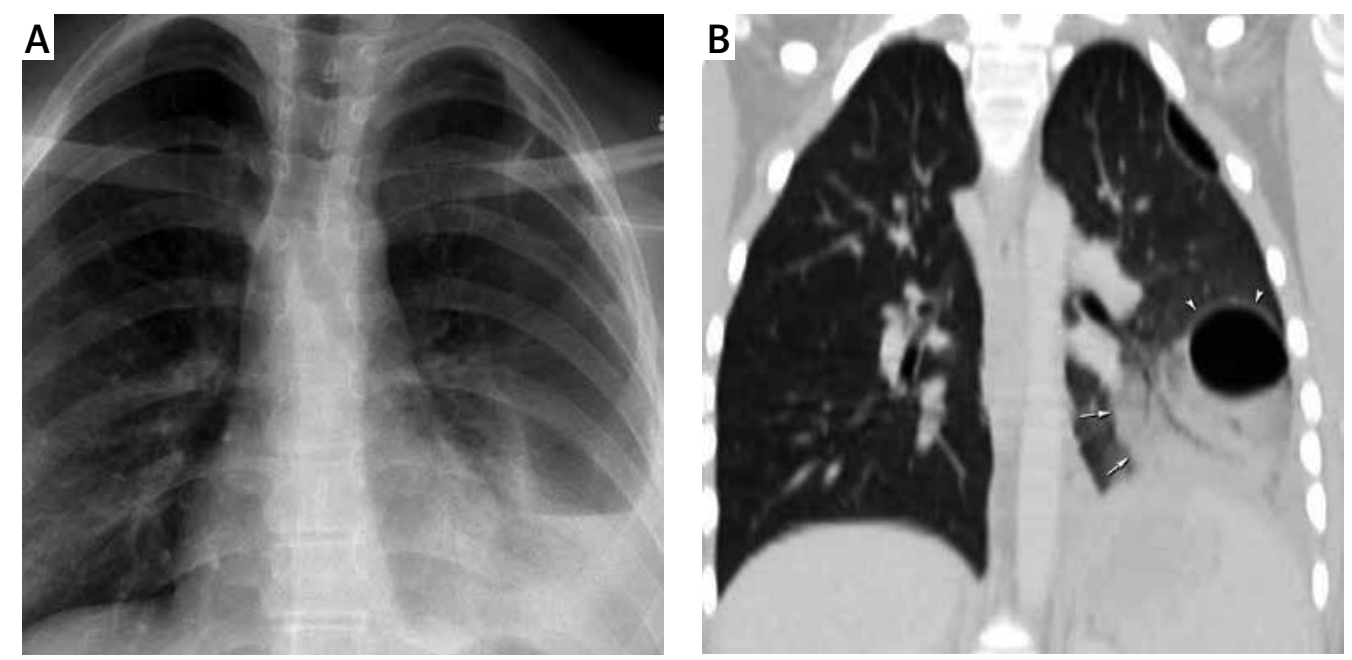

Figure 1. A - Posterioranterior chest X-ray shows a homogeneous opacity in the left lower lobe with some pleural effusion. B - In coronal reconstruction pulmonary window, left lower lobe consolidation (arrows) is accompanied by a large air cyst (arrowhead) 


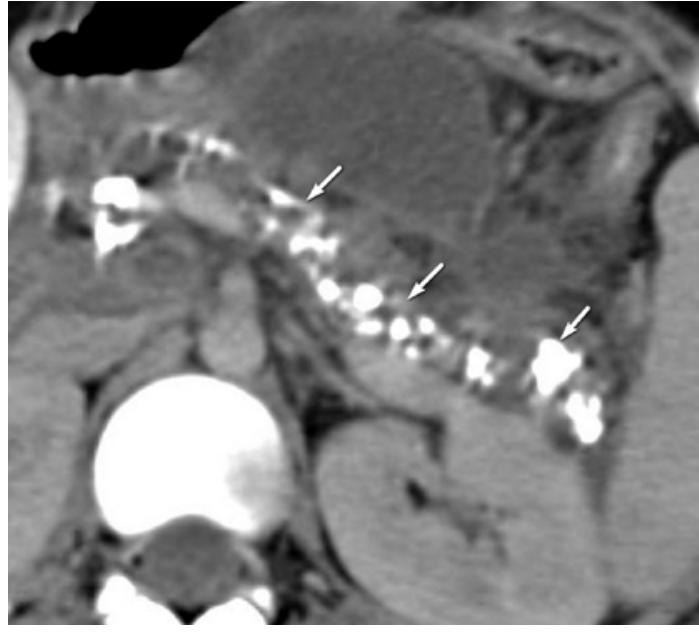

Figure 2. On upper abdominal sections of lung CT, pancreatic atrophy and parenchymal calcifications (arrows) are remarkable

pediatric age of the patient, hemorrhagic effusion was unexpected and a thoracic computed tomography (CT) was performed for a specific diagnosis. Computed tomography scan revealed a left lower lobe consolidation accompanied by air cysts (Figure $1 \mathrm{~B}$ ). Pancreatic parenchyma contained calcifications in upper abdominal CT sections (Figure 2). An upper abdominal MRI was performed to clarify the etiology of pancreatic calcifications and extent of the pleural tubular structures within the peritoneal cavity. On MR images pancreatic pa-
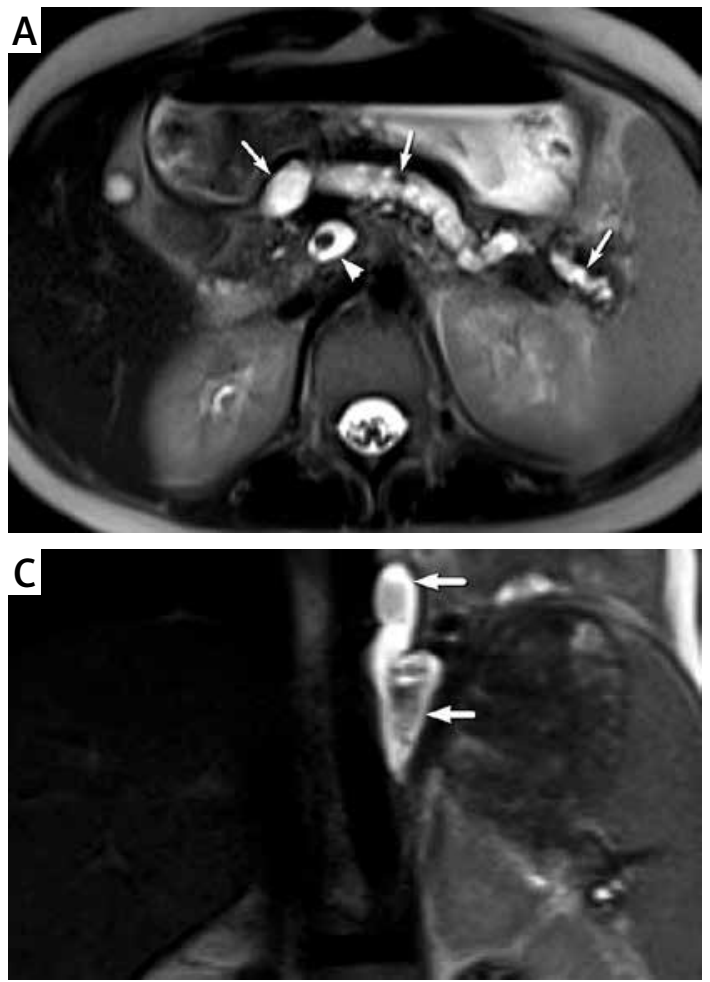

renchyma was diffusely atrophic. The pancreatic duct was diffusely dilated (Figure $3 \mathrm{~A}$ ). In the pancreatic head a tubular structure in communication with the pancreatic duct extending superiorly to the left pleural space was seen (Figures $3 \mathrm{~B}, \mathrm{C}$ ). T2-weighted MR images well depicted the fistulous connection between the pancreatic duct and the pleural space. The patient was diagnosed with pancreaticopleural fistula and chronic pancreatitis. A 7 Fr stent was inserted into the main pancreatic duct endoscopically so that drainage was obtained. The patient was called for follow-up 2 months later. On abdominal CT scan pleural effusion regressed and fistulas disappeared (Figure 4).

The PPF occurs due to rupture of the main pancreatic duct or side branches secondary to inflammation of or trauma to the pancreas [4]. It is hypothesized that duct disruption develops posteriorly; pancreatic secretion flows into the retroperitoneum and may dissect through the aortic or esophageal hiatus into the mediastinum and form a pleural fistula. It is a very rare entity, especially in children. The most common symptoms are related to the pleural effusion that delays the diagnosis [1]. These include dyspnea in $65 \%$ of patients, cough in $27 \%$, and chest pain in $23 \%$ of them. Analysis of pleural fluid reveals extremely elevated levels of pleural fluid amylase and lipase, and high albumin content [5]. A chest CT scan is valuable in detecting the amount of fluid in the pleural space and distinguishing pleural effusion from empyema. It helps to identify intrathoracic causes of effusion. However, in case of a PPF, the

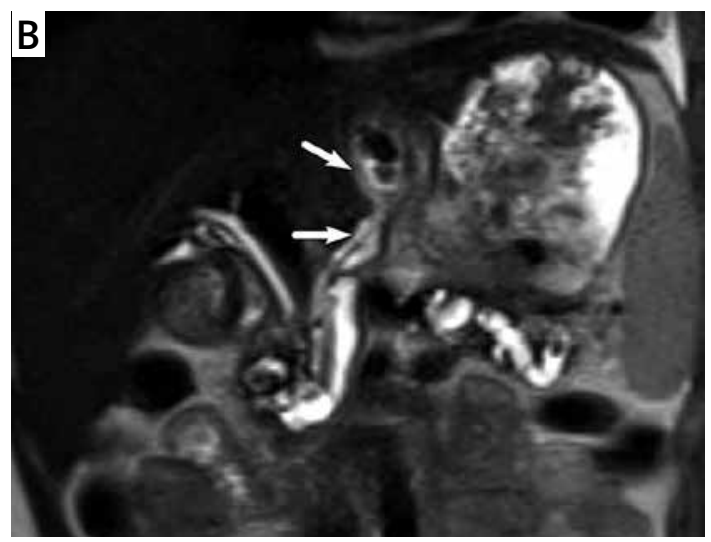

Figure 3. A - On axial T2W MR image, pancreatic duct (arrows) is dilated with a diameter of $7 \mathrm{~mm}$. At the head of the pancreas another cystic structure appears with a hypointense calcification (arrowhead) in it. B, C - In consecutive coronal T2W images a tubular structure (arrows) beginning in the uncinate process and extending superiorly to the pleural space is well depicted 


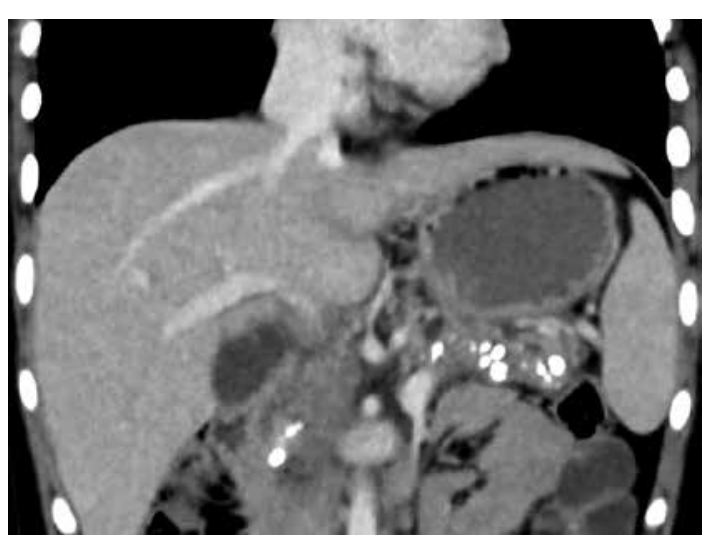

Figure 4. Coronal reformatted upper abdominal CT scan shows a normal left lower lobe of the lung and persisting pancreatic calcifications. However, a tubular structure which connects the pancreatic parenchyma and left pleural space cannot be seen

fistulous connection between the pancreatic duct and pleura is not always obvious on CT images. The CT was performed in most studies reporting PPFs, but it was able to present the fistula only in 33-47\% of cases [6]. The CT has a limited contrast resolution to demonstrate a narrow and tortuous canal with poorly enhancing walls. The MR cholangiopancreatography (MRCP) is considered the method of choice for suspected PPF [2-4]. The advantage of MRCP is noninvasive detection of the fistula even in case of severe strictures of the pancreatic duct. It allows one to understand the ductal anatomy along with pathologic changes in adjacent structures, which helps to plan the optimal treatment choice. It has been proposed that endoscopic retrograde cholangiopancreatography (ERCP) should be reserved only for patients with inconclusive $M R$ or scheduled for endoscopic treatment [3-5].

The PPF should be kept in mind in large pleural effusion, usually one-sided in case of acute or chronic pancreatitis. The MRI and MRCP have an important role in both noninvasive diagnosis of the pathology and determining the etiology at the same time. The ERCP should be reserved for the cases to be treated endoscopically.

\section{Conflict of interest}

The authors declare no conflict of interest.

\section{References}

1. Tay CM, Chang SK. Diagnosis and management of pancreaticopleural fistula. Singapore Med J 2013; 54: 190-4.

2. Thai TC, Riherd DM, Rust KR. MRI manifestations of pancreatic disease, especially pancreatitis, in the pediatric population. AJR Am J Roentgenol 2013; 201: W877-92.

3. Machado NO. Pancreaticopleural fistula: revisited. Diagn Ther Endosc 2012; 2012: 815476.

4. Tuncer D, Karabulut N, Yağci AB. Thoracopancreatic fistula: imaging findings (case report) [Turkish]. Tani Girisim Radyol 2004; 10: 238-41.
5. Fujiwara T, Kamisawa T, Fujiwara J, Tu Y, Nakajima H, Egawa N. Pancreaticopleural fistula visualized by computed tomography scan combined with pancreatography. JOP 2006; 7: 230-3.

6. Wypych K, Serafin Z, Gałązka P, et al. Pancreaticopleural fistulas of different origin: report of two cases and a review of literature. Pol J Radiol 2011; 76: 56-60. 